ISSN 0258-7122

Bangladesh J. Agril. Res. 40(3): 381-390, September 2015

\title{
SOME BIOLOGICAL PARAMETERS OF BRINJAL SHOOT AND FRUIT BORER, LEUCINODES ORBONALIS GUENEE (LEPIDOPTERA: PYRALIDAE) ON POTATO IN LABORATORY CONDITION
}

\author{
M.A. MANNAN ${ }^{1}$, K.S. ISLAM ${ }^{2}$, M. JAHAN ${ }^{2}$ AND N. TARANNUM ${ }^{3}$
}

\begin{abstract}
Studies were made on the biology of brinjal shoot and fruit borer (BSFB), Leucinodes orbonalis Guenee feeding on peeled potato tubers as host in the laboratory. It was observed that moths were active at night for mating, oviposition and adult emergence. Adult emergence started just after sunset and it was maximum $(88.90 \%)$ during the first half of the night. Maximum mating occurred at late night where $90.80 \%$ mating occurred in the first night of adult emergence. Oviposition occurred in the second night of emergence when $86.62 \%$ of eggs were deposited during the first half of the night. A female laid 288.05 eggs in 2.65 days in summer and 185.55 eggs in 2.70 days in winter. The egg hatching and larval and pupal period of BSFB were 4.13, 10.40 and 6.60 days, respectively in summer and 6.90, 14.50 and 10.65 days in winter. BSFB needs 10.40 and 14.50 days to complete its larval period in summer and winter, respectively. Pupal period lasted for 5-13 days. Life cycle from egg to adult was 17-44 days. The longevity of male and female adult was 3.50 and 6.20 days in summer and 4.85 and 8.90 days in winter. Temperature in two seasons showed variations in the biology of BSFB.
\end{abstract}

Keywords: Biology, adult longevity, brinjal shoot and fruit borer, mating, oviposition, larval and pupal period.

\section{Introduction}

Brinjal (Solanum melongena $\mathrm{L}$.) is one of the most popular and year-round vegetable, cultivated widely in Bangladesh and covers about $15 \%$ of the total vegetable area of the country (Rahman, 2005) with an average yield of $6.03 \mathrm{t} / \mathrm{ha}$ (Anon, 2009). It is the leading vegetable in the country and ranks first among summer and winter vegetables in terms of total acreage and cultivation by small farmers, low income consumers and commercial growers. Brinjal, an economically important commercial crop, is reported infestation by more than 36 pests (Regupathy et al., 1997) from the time of its planting to harvest. Among them brinjal shoot and fruit borer is considered to be the most serious pest of brinjal and it has become a very serious production constraint in all brinjal growing countries (Alam et al., 2003). It is very difficult to control as it feeds inside the shoots and fruits (Ghosh and Senapati, 2009). Sometimes, the yield

${ }^{1}$ Regional Agricultural Research Station, Jamalpur, ${ }^{2}$ Department of Entomology, Bangladesh Agricultural University, Mymensingh, ${ }^{3}$ Sher-E-Bangla Agricultural University, Dhaka, Bangladesh. 
loss caused by this pest has been estimated more than $85 \%$ (Rashid et al., 2003) in Bangladesh, 85.8\% (Patnaik, 2000) and 75\% (Singh et al., 2005) in India. Over $95 \%$ of farmers recognized BSFB as the most serious pest of brinjal and nearly all of them used only chemical insecticides to combat this pest (Alam et al., 2003).

Indiscriminate use of systemic insecticides makes the vegetables poisonous, ecologically unsafe and economically unviable. It is easy to replace the poisonous chemicals with the knowledge of the nature and behaviour of BSFB. Very few farmers had knowledge on the biology of BSFB. Insect control with insecticides and other methods is based on the availability of data on insect biology, ecology and population dynamics. It is important to know the life cycle of an insect so that control mechanisms may be incorporated at the most susceptible stage of the life cycle. It is necessary to understand the biology of BSFB for reducing crop damage. Therefore, the present study has been undertaken to know some biological parameters of BSFB.

\section{Materials and method}

The biology of BSFB was studied during March, 2008 to April, 2009 in the laboratory, Department of Entomology, BAU, Mymensingh, Bangladesh. Infested fruits were collected from the unsprayed brinjal field and were kept in tin made tray like open container with dried brinjal leaves (Plate 1). Through completing the larval stage the full fed larvae came out from the infested brinjal fruits and go to pupation in the dried brinjal leaves. A large number of pupae were collected from the tray (Plate 2) and left in a glass jar. The mouth of the glass jar was then covered with a small piece of mosquito net to allow the pupae to develop into adults (Plate 3). After adult emergence, the male and female adult moths were collected from the glass jars. A pair of adults (one male and one female) was transferred into a both side open cylindrical glass jar (Plate 4) containing a few pieces of green papers inside. The inner surface of the glass jar was wrapped with green papers to make the environment of the jar somewhat green like leaves of brinjal. Immediately after transferring the adults both the open ends were covered carefully with small pored net so that the moths were not injured during the process. Mating, adult behavior and oviposition were recorded in the twenty same cylindrical jars. BSFB usually lays eggs on the brinjal leaves and twigs both of which are rough surfaced. In preliminary observation it was also evident that BSFB female prefers to deposit its eggs in a place of rough surface. The fine meshed net was found to be a preferred surface for egg deposition of BSFB. This type of net was used to cover the cylinder with the objective to encourage the females to lay eggs on it. Sugar solution of 5\% soaked in cotton was placed inside the cylinder to provide nourishment for the adults during the period of oviposition. The pair of moths was transferred to another 
similar jar after 24 hours and maintained following the same procedure. This was continued so long the moths survived. Twenty mated females were used separately as 20 replications for recording the egg laying trend. After removal of adults the green papers and the fine meshed net were checked thoroughly for the presence of BSFB egg.
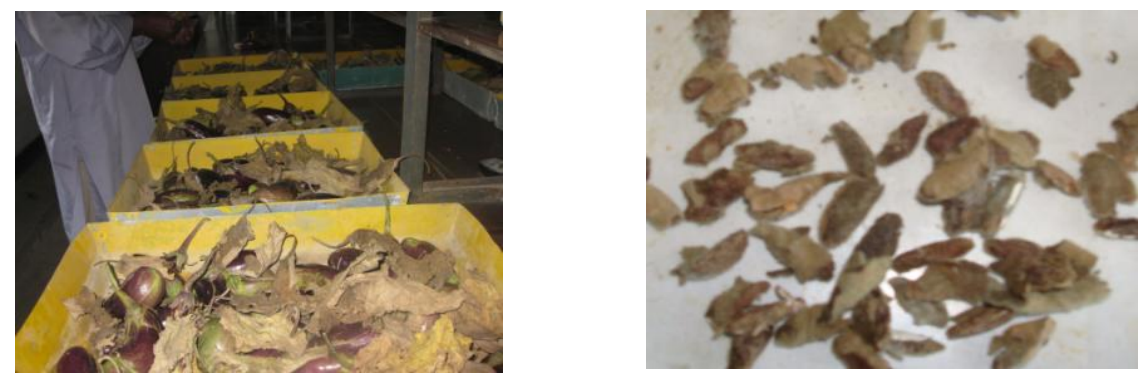

Plate 1: Infested fruits with brinjal leaves. Plate 2: Collected pupae from the tray.

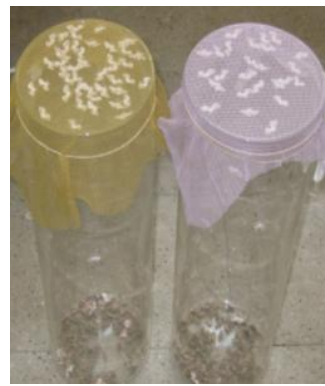

Plate 3: : BSFB adult emerged from pupae in glass cylinder

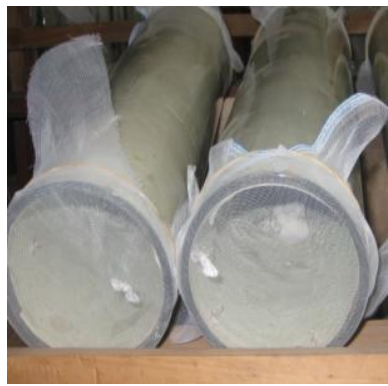

Plate 4: One pair of adult (male and female) within the rearing chamber

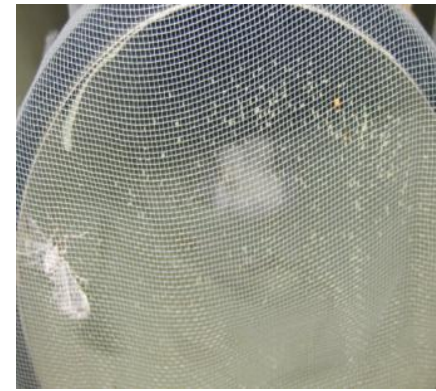

Plate 5: Egg mass of BSFB

As expected the female laid all the eggs on the net. There was no trace of eggs on the green papers. The eggs on the net were very tiny and visualized properly with the help of magnifying glass. Then these were counted and it was continued until the death of the female. This counting was done at mid night and early in the morning as it was observed to lay eggs after sunset and no eggs were laid in day time. After counting, the net with eggs was placed in a plastic film container and allowed to hatch. For all the batches of eggs, the same procedure was maintained. All the batches of eggs of an individual were added to get the fecundity of the female. Twenty females were observed for laying their eggs (Plate 5). The age specific egg laying pattern of the female was determined. The eggs laid by a female per day from the $1^{\text {st }}$ oviposition day to the last oviposition day were counted daily. The longevity of the adults was recorded also.

Net with eggs were cut into several pieces carefully with minimum damage and kept in plastic film container and allowed to hatch. The eggs were observed for 
hatching everyday. The time of egg hatching was also recorded. Counting of the number of egg hatching was done from early in the morning to till $2.00 \mathrm{PM}$. Once the eggs hatched into neonate larvae the duration of the incubation period was recorded. The mean incubation period and percentages of hatching were calculated. After hatching, 40 neonate larvae were released on whole peeled potato with the help of soft hair brush for feeding. Immediately after releasing on the peeled potato the newly hatched larvae were allowed to settle there. In earlier experiment laboratory rearing technique of BSFB on the peeled potato was developed. The development of larvae of each generation was observed. Peeled potato infested with neonate larvae was observed for the development of larvae. Once the larval period is about to be completed, they came out from the host potato. The larval duration was recorded. Pre-pupae were left in a tray with dry leaves of brinjal for pupation to provide favorable environment for pupation. The pre-pupae were observed carefully for any change to become a pupa. All the prepupae and pupae were left undisturbed in a tray until the adult emergence. The pupal period was recorded. The total development periods were also recorded. To study the behavior of the adult emergence a number of pupae were kept in a glass cylinder and observed for adult emergence. In a preliminary study in the laboratory it was found that adult started emerging from the pupae just after sunset and continued up to sun rising and no adults emerged in day time. Therefore, the number of adult emergence were recorded at two times viz., mid night and early in the morning. The percentage of adult emergence was calculated at first half and second half of night.

\section{Results and discussion}

\section{Mating behavior}

BSFB moths were found active at night when the mating took place. As revealed from the preliminary observation that maximum percentage of adult emergence (88.90\%) occurred at first half of the night (Table 1). Mating frequency was found to vary with the adult emergence time. The percentage of mating was 90.80 in the night of adult emergence and it was 9.20 in the next night (Table 2). The mean of mating period was 35.02 minutes in summer and 43.27 minutes in winter (Table 3). Singh and Singh (2001a) reported mating more than once in the life span of female which occurred at night or very early hours in the morning. Yasuda and Kawashaki (1994) observed the copulation of male and female at 4.40 AM which lasted for 43 minutes. Das and Islam (1982) showed that the virgin 1-day old females began calling from 18:15 to 23.45 hours and duration was 33 minutes. Kavitha et al., (2008) showed that mating took place on the same or next day after emergence. Prabhat and Johnsen (2000) reported that the feeding and mating activities occurred during night and mating lasted for about 16 minutes. The findings of the above authors supported the present investigation on mating behavior of adult moths of orbonalis L. 
Table 1. Percentage of adult emergence and oviposition of brinjal shoot and fruit borer in different times of night.

\begin{tabular}{l|c|c|c|c}
\hline \multirow{2}{*}{ Parameters } & \multicolumn{2}{|c|}{ First half of the night } & \multicolumn{2}{c}{ Second half of the night } \\
\cline { 2 - 5 } & Range & Mean \pm SE & Range & Mean \pm SE \\
\hline Adult emergence (\%) & $84-95$ & $88.90 \pm 1.07$ & $5-16$ & $11.10 \pm 1.07$ \\
Egg laying (\%) & $73.83-96.33$ & $86.62 \pm 2.53$ & $3.67-26.17$ & $13.38 \pm 2.53$ \\
\hline
\end{tabular}

Table 2. Percentage of mating and ovipositing female of brinjal shoot and fruit borer in two nights.

\begin{tabular}{l|c|c|c|c}
\hline \multirow{2}{*}{ Parameters } & \multicolumn{2}{|c|}{ First night } & \multicolumn{2}{c}{ Second night } \\
\cline { 2 - 5 } & Range & Mean \pm SE & Range & Mean \pm SE \\
\hline Mating (\%) & $88-94$ & $90.80 \pm 0.59$ & $6-12$ & $9.20 \pm 0.59$ \\
Egg laying (\%) & $75-98$ & $85.90 \pm 2.88$ & $2-25$ & $14.10 \pm 2.88$ \\
\hline
\end{tabular}

\section{Oviposition behaviour}

Egg laying always occurred at night. Generally oviposition started during the next night after emergence and mating. Maximum percentage of $(86.62 \%)$ egg laying occurred at first half of the night and rest of them were in the second half of the night (Table 1). There were $85.90 \%$ females to start egg laying in the first night and $14.10 \%$ were in the second night (Table 2). Although females were found to survive about a week but effective egg laying period was first three days. The eggs were distributed in mass or singly in a scattered form. A range of 40-60 eggs were found in a mass. Singh and Singh (2001b) reported that the female laid eggs within a day or second day after mating. Singh and Singh (2001a) reported that the laying of eggs started on the same day of mating and continued till fourth day with an average preoviposition and ovipositional period 1.35 and 2.09 days, respectively. The number of eggs gradually decreased by each day. The egg laying activities of the female was reported by Prabhat and Johnsen (2000), Alam et al., (2003) and Rahman (2005). The latter author reported that eggs were laid during the later part of the night to the early hours of the morning. Gupta and Kauntey (2007) reported that the average oviposition period of BSFB was 2.46 days. Harit and Shukla (2003) expressed the similar opinion indicating that the female BSFB moth starts laying eggs on the same day or a day after mating. The mean oviposition period was observed in this study was 2.65 days in summer and 2.70 days in winter (Table 3). Harit and Shukla (2003) and Gupta and Kauntey (2007) reported 2.1 and 2.46 days as oviposition period which was similar to the present study. However, all the findings showed that the oviposition period of BSFB is very short. This indicated that the female emerged with full compliment of eggs which were deposited in short time starting as early as possible. 
Table 3. Different biological parameters of brinjal shoot and fruit borer in two seasons.

\begin{tabular}{l|ccccc}
\hline \multirow{2}{*}{ Parameters observed } & \multicolumn{2}{c|}{ Summer } & \multicolumn{2}{c}{ Winter } \\
\cline { 2 - 5 } & Range & Mean \pm SE & Range & Mean \pm SE \\
\hline Preoviposition period (days) & $1.15-1.24$ & $1.21 \pm 0.32$ & $1.08-1.21$ & $1.10 \pm 0.52$ \\
Fecundity (eggs/female) & $198-387$ & $288.05 \pm 2.32$ & $100-281$ & $185.55 \pm 2.52$ \\
Oviposition period (days) & $1-4$ & $2.65 \pm 0.04$ & $1-4$ & $2.70 \pm 0.04$ \\
Egg hatching period (days) & $3.5-4.21$ & $4.13 \pm 0.01$ & $5.0-8.0$ & $6.90 \pm 0.05$ \\
Egg hatching (\%) & & & & \\
Morning & $87-95$ & $90.37 \pm 1.06$ & $83-94$ & $87.41 \pm 0.18$ \\
After morning to noon & $5-11$ & $9.63 \pm 1.06$ & $4-9$ & $12.59 \pm 0.18$ \\
Overall egg hatching (\%) & $80-100$ & $94.05 \pm 0.30$ & $28-77$ & $60.80 \pm 0.68$ \\
Larval period (days) & $8-16$ & $10.40 \pm 0.11$ & $11-25$ & $14.50 \pm 0.18$ \\
Pupal period (days) & $5-9$ & $6.60 \pm 0.05$ & $9-13$ & $10.65 \pm 0.06$ \\
Life cycle (egg to adult) (days) & $17-28$ & $21.18 \pm 0.14$ & $23-44$ & $31.95 \pm 0.21$ \\
Longevity of adult (days) & & & & \\
Male & $2-5$ & $3.50 \pm 0.05$ & $3-7$ & $4.85 \pm 0.06$ \\
Female & $5-8$ & $6.20 \pm 0.05$ & $7-11$ & $8.90 \pm 0.07$ \\
Mating duration (minutes) & $33-45$ & $35.02 \pm 2.05$ & $28-50$ & $43.27 \pm 1.07$ \\
\hline
\end{tabular}

\section{Fecundity and egg viability}

After mating the female moth of $L$. orbonalis laid a mean of 288.05 eggs in summer and 185.55 eggs in winter (Table 3). The overall mean percentage of egg hatching was 94.05 (ranged from 80-100\%) in summer and 60.80 (ranged from 28$77 \%)$ in winter. The egg hatching period ranged from 3.5 to $4.21(x=4.13)$ days in summer and 5 to $8(x=6.90)$ days in winter. It is important to note that eggs hatched early in the morning. Usually in the morning $90.37 \%$ eggs hatched in summer (5.0-7.0 AM) and 87.41\% in winter (7.0-9.0 AM). Rest of the eggs hatched at 7:00-14:00 hours in summer and 9:00-14:00 hours in winter (Table 3). Egg laying started just after sunset and no egg was laid during day time.

Singh and Singh (2001a) reported that on an average 174.95 eggs were laid by a female and the viability of eggs was $82.61 \%$. Alam et al., (2003) reported that the number of eggs laid by a female varies from 80 to 253. An adult female laid as few as 8 to as many as 295 eggs during its lifetime with an average of 118 eggs (PhilRice, 2007). Kavitha et al., (2008) reported that the average number of eggs laid by an individual female was 170 . The results of the present study showed that the number of eggs laid per female and percentage of egg hatching was higher in summer than the winter which might be due to higher temperature in 
summer. The number of eggs laid per female and percentage of egg hatching reported by the above authors were lower than that found in summer in present study. However, the data of fecundity in winter is similar to those of the above reports. Environmental conditions influence the biology of many insects including the fecundity.

\section{Larval and pupal development}

After hatching, the neonate larvae which were released on the potato tubers bored into the tubers. They completed their larval period on this host. The neonate larva completed its larval period in 10.40 days (8-16 days) during summer and 14.50 days (11-25 days) during winter (Table 3). Rahman (2005) showed that the larval period was 12-15 days during summer while it was 14-22 days during winter season. A larva of $L$. orbonalis completes its larval development in 15-20 days (Talekar et al., 1999). The average larval period was 18.66 days (Singh and Singh, 2001a), 12.80 days (Gupta and Kauntey, 2007) and 16.32 days (Kavitha et al., 2008a). It is reported by several authors that BSFB larva completes its total development period in 5 instars. In the present study five larval instars were found during different activities. It became difficult to study the instar wise developmental period in potato host as the left exuvae were not clearly visible due to similarity with the color of potato. For this reason no attempt was made to conduct the study on instar wise development period. Variation of larval developmental period in summer and winter noticed in the present study was solely the influence of higher and lower temperature in these two seasons. The effect of different hosts such as potato used in the present study and different artificial diets used by different authors caused such variation of larval development.

The full fed larvae moved out of the potato tubers to pupate in the supplied dried brinjal leaves, the usual substrate for pupation. The pupal period was 6.60 days (5-9 days) in summer and 10.65 days (9-13 days) in winter (Table 3). Rahman (2005) showed that the pupal period was 7-10 days during summer while it was 13-15 days during winter. Almost similar pupal period was reported by Rahman (2005) and Kavitha et al., (2008) and also by Gupta and Kauntey (2007). It is evident from the present study and reports of other authors that BSFB needs around a week for completion of its pupal period.

\section{Total development period}

The total development period (egg-adult) ranged from 17.0 to 28.0 days $(x=21.18)$ in summer and 23.0-44.0 days $(x=31.95)$ in winter (Table 3). Mathur et al., (2000) showed that the total development period was found to be $28.2 \pm 1.2$ days and $37 \pm 2.31$ days in summer and winter, respectively. A range of 22 to 27 days as total developmental period of brinjal shoot and fruit borer was reported by PhilRice (2007) and a mean of 28.82 days was reported by Gupta and 
Kauntey (2007). Singh and Singh (2001a) described the life cycle of the brinjal shoot and fruit borer and showed 26 to 39 days developmental period of BSFB with 10 generations in a year. It is clear from the data that BSFB requires 1.5 times higher periods to complete its development in winter than that of summer. Although the effect of temperature was not studied in this experiment the results indicated that the rate of development of BSFB seemed to be directly proportional to the temperature.

\section{Adult emergence}

Most of the adults (88.90\%) emerged during the first half of the night and rest of the adults emerged in the second half of the night (Table 1). During the day adults remained inactive on the lower surface of the host leaf and were not usually seen. They were found to be active at night for their mating and oviposition purposes. At night they were mostly active from $20.00 \mathrm{~h}$ to $22.00 \mathrm{~h}$ (Alam et al., 2003).

\section{Adult longevity}

Longevity of male and female of BSFB moth is shown in Table 3. The longevity of female moth was higher than the male moth. The male adult survived in 2-5 days $(x=3.50)$ in summer and 3-7 days $(x=4.85)$ in winter. The female adult longevity was 5-8 days $(x=6.20)$ in summer and 7-11 $(x=8.90)$ days in winter (Table 3). Singh and Singh (2001a) reported that the male and female moth of $L$. orbonalis was found to survive on an average for 3.53 days (2-5 days) and 5.80 days (2-8 days). The longevity of male and female was 4.0 days and 7.5 days, respectively (Bang and Corey, 1991). On an average the longevity of adult was 4-8 days reported by PhilRice (2007). Kavitha et al., (2008) reported that the longevity of male and female was 3.50 days and 5.70 days, respectively. Reports on the longevity of male and female BSFB moth by Kavitha et al., (2008) was 3.5 and 5.70 days, respectively which is similar to the results of the present study. As per findings of Gupta and Kauntey (2007) the longevity of BSFB moth was very short which is different from the results of present study as well as reports of other authors. There might be some reasons for such short duration but no single individual moth lived for such short period in the environmental condition of the present study. Adult longevity was longer in winter than summer. Female longevity was about 2-fold higher than the male.

\section{References}

Alam, S.N., Rashid, M.A., Rouf, F.M.A., Jhala, R.C., Patel, J.R., Satpathy, S., Shivalingaswamy, T.M., Rai, S., Wahundeniya, I., Cork, A., Ammaranan, C. and Talekar, N.S. 2003. Development of an integrated pest management strategy for eggplant fruit and shoot borer in South Asia. Technical Bulletin No. 28. AVRDC 
Publication Number 03-548. AVRDC-The World Vegetable Centre, Shanhua, Taiwan. 56p.

Alam, S.N., Hossain, M.I., Rouf, F.M.A., Jhala, R.C., Patel, M.G., Raith, L.K., Sengupta, A., Baral, K., Shylesha, A.N., Satpathy S., Shivalingaswamy, T.M., Cork, A. and Talekar, N.S. 2006. Implemntation and promotion of an IPM strategy for control of eggplant fruit and shoot borer in South Asia. Technical Bulletin No. 36. AVRDC Publication Number 06-672. AVRDC-The World Vegetable Centre, Shanhua, Taiwan. 74p.

Anonymous. 2009. Production of vegetables. Statistical Year Book of Bangladesh, BBS. $154 \mathrm{p}$.

Bang, L.A. and Corey, F.M. 1991. Life history of an eggplant shoot and fruit borer, Leucinodes orbonalis Guenee (Lepidoptera:Pyralidae). CMU J. Sci. 4(1): 45-61.

Das, G.P. and Islam, M.A. 1982. Effects of age on the calling behaviour of the brinjal shoot and fruit borer, L. orbonalis (Lepidoptera:Pyralidae). Bangladesh J. Zool. 10(2): 120-125.

Ghosh, S.K. and Senapati, S.K. 2009. Seasonal fluctuation in the population of Leucinodes orbonalis Guenee in the sub-himalayan region of West Bengal, India and its control on eggplant (Solanum melongena). Prec. Agril. 10(5): 443-449.

Gupta, Y.C. and Kauntey, R.P.S. 2007. Biology of shoot and fruit borer, Leucinodes orbonalis Guenee of brinjal, Solanum melongena Linn. at Mathura, Uttar Pradesh, India. Asian J. Exp. Sci. 21(1): 155-160.

Harit, D.N. and Shulka, G.R. 2003. Laboratory biology of brinjal shoot and fruit borer, Leucinodes orbonalis Guenee (Lepidoptera:Pyralidae). J. Exp. Zool. 5(2): 133-140.

Kavitha, V.S., Revathi, N. and Kingsley, S. 2008. Biology of brinjal pest, Leucinodes orbonalis Guenee of Erode region in Tamil Nadu. J. Entomol. Res. 32(3): 255-257.

Mathur, A., Saxena, A. and Jain, L.V. 2000. The seasonal effects on the biology of Leucinodes orbonalis Guenee during summer and winter. Asian J. Exp. Sci. 13(1\&2): 1-4.

Patnaik, H.P. 2000. Flower and fruit infestation by brinjal shoot and fruit borer, Leucinodes orbonalis Guenee-damage potential vs. weather. Veg. Sci. 27(1): 82-83.

PhilRice. 2007. Integrated pest management in rice-vegetable cropping systems. Maligaya, Science City of Munoz, Nueva Ecija. 73p.

Prabhat, K. and Johnsen, S. 2000. Life cycle studies on fruit and shoot borer (Leucinodes orbonalis) and natural enemies of insect pests of eggplant (Solanum melongena). J. Appl. Biol. 10(2): 178-184.

Rahman, M.M. 2005. IPM technologies of different crops potential for field trial generated at the Department of Entomology, BSMRAU, Gazipur. Paper presented at IPM operation workshop organized by the DANIDA-DAE-SPPS project and held on March 30 at DAE, Khamarbari, Dhaka, Bangladesh.

Rashid, M.A., Alam, S.N., Rouf, F.M.A. and Talekar, N.S. 2003. Socio economic parameters of brinjal pest control in Jessore district of Bangladesh. Technical 
Bulletin No. 29. Shanbua, Taiwan. AVRDC-The world vegetable centre. AVRDC publication No. 03-556. 29p.

Regupathy, A., Armes, N.J., Asoken, G., Jadhav, D.R., Soundarajan, R.D. and Russell, D.A. 1997. Best method for insecticide resistance management of Helicoverpa armigera. In: International Conference on Integrated Approach to Combating Resistance. A.L. Devonshine (ed.), April 14-16, 1997. IACR, Rothamsted, Harpendle, UK. 116p.

Singh, N.P., Thakur, N.S.A., Shyclesha, A.N. and Biswas, S. 2005. Implementation and Promotion of IPM technology for the control of eggplant shoot and fruit borer (Leucinodes orbonalis Guenee) in Meghalaya and Tripura. Publication No.-17. AVRDC, Post Box: 42, Sanghua, Taiwan 741.

Singh, Y.P. and Singh, P.P. 2001a. Biology of shoot and fruit borer (Leucinodes orbonalis Guenee) of eggplant (Solanum melongena $\mathrm{L}$ ) at medium high altitude hills of Meghalaya. Indian J. Entomol. 63(3): 360-368.

Singh, Y.P. and Singh, P.P. 2001b. Lab biology of shoot and fruit borer (Leucinodes orbonalis Guenee) of eggplant at medium high altitude hills of Meghalaya. Indian J. Entomol. 63(4): 373-376.

Talekar, N.S., Lin, M.Y. and Hwang, C.C. 1999. Rearing eggplant fruit and shoot borer. A slide set and illustrated guide. AVRDC publication no. 99-486, April 1999. AVRDC, PO Box 42, Shanhua, Taiwan 741 ROC. 12p. (Text in Ent) (AVRDC staff publication) (SB348. ESREP-102).

Yasuda, K. and Kawasaki, K. 1994. Mating behaviour of eggplant fruit borer, Leucinodes orbonalis Guenee (Lepidoptera:Pyralidae) and capture of males in virgin female traps. Japanese J. Appl. Entomol. Zool. 38(4): 302-304. 